\title{
SURFACE STUDY OF NIOBIUM SAMPLES USED IN SUPERCONDUCTING RF CAVITY PRODUCTION*
}

\author{
Qing $\mathrm{Ma}^{\dagger}$ and Richard A. Rosenberg, Argonne National Laboratory, Argonne, IL 60439
}

\begin{abstract}
We have initiated an effort to study the $\mathrm{Nb} /$ oxide interface and its effect on rf cavity performance. The oxide layer on processed cavity surfaces is dominantly $\mathrm{Nb}_{2} \mathrm{O}_{5}$, which has a high secondary electron yield that may be detrimental to cavity performance. This effort will focus on developing new processes to remove the oxide layer by an easily achievable means. In this presentation, we show some preliminary results of a surface study of the metal/oxide interfaces on $\mathrm{Nb}$ samples that have undergone different surface processes usually used in cavity production. The results suggest that $\mathrm{Nb}_{2} \mathrm{O}_{5}$ is not stable when subjected to heat treatment of $\sim 250{ }^{\circ} \mathrm{C}$, and that it converts into monovalent or even subvalent oxides that are metallic in nature. Further studies will try to pinpoint the factors that influence surface properties.
\end{abstract}

\section{INTRODUCTION}

Superconducting rf cavities represent the potential of high-energy particle accelerator facilities to provide highgradient acceleration. Problems encountered during if cavity development, such as electron multipacting and the field emission of impurity particulate, have largely been solved and gradients as high as $25 \mathrm{MV} / \mathrm{m}$ are now achievable. However, new issues appear to be limiting further increases of the accelerating gradient. Among other things, the pentavalent niobium oxide layer $\left(\mathrm{Nb}_{2} \mathrm{O}_{5}\right)$ remaining on the $\mathrm{Nb}$ rf cavity surface after chemical or electrochemical processing has emerged as a potentially detrimental cause for the $\mathrm{Q}_{0}$-factor deterioration of the $\mathrm{rf}$ cavity at high gradients.

\section{EXPERIMENTAL}

$\mathrm{Nb}$ samples used in this study were provided by CERN (Switzerland) and prepared by either Buffered Chemical Polishing (BCP) or electro-polishing (EP), the standard procedures for rf cavity preparations. In general, more than $100 \mu \mathrm{m}$ surface materials were removed. The polished surfaces were rinsed alternatively in deionized water, nitric acid, and hydrofluoric acid. Some of the samples were rinsed by 100-bar high-pressure water for $2 \mathrm{~min}$. The EPtreated surfaces were smoother than BCP-treated ones. The samples were shipped to Argonne in $\mathrm{N}_{2}$-filled bags.

X-ray photoelectron spectroscopy (XPS) was used for surface characterization. The $\mathrm{Mg}$ Ka radiation $(1253.6 \mathrm{eV})$ emitted from a $\mathrm{Mg}$ target was used to excite the sample surfaces. A hemispheric mirror electron energy analyzer was used to register the energy distribution curves of emitted photoelectrons. It was operated in the constantanalysis energy mode. Pass energy of $20 \mathrm{eV}$ was used for collecting $\mathrm{C} 1 \mathrm{~s}, \mathrm{O} 1 \mathrm{~s}$, and $\mathrm{Nd} 3 \mathrm{~d}$ data. The base pressure of the analysis system is $2 \times 10^{-10}$ Torr. The surfaces were also subjected to heat treatment at $250{ }^{\circ} \mathrm{C}$ in vacuum by passing current through a $\mathrm{W}$ filament located near the back of the sample. A thermocouple measured the surface temperature.

The secondary electron yield (SEY) properties of the surfaces were also measured using a retarding potential method [1]. The electron beam current $I_{e}$ was determined using a Faraday cup. Electron current density of $3 \times 10^{-4}$ $\mathrm{A} / \mathrm{cm}^{2}$ was used. The SEY was measured as a function of impact electron energy, calculated by $\left(1-I_{s} / I_{e}\right)$. The sample current $I_{s}$ was recorded by an electrometer.

\section{RESULTS AND DISCUSSION}

Figure 1 shows the XPS spectra collected on the surfaces of some of the samples in as-received forms. Samples A and B were both EP treated, and samples C and D were BCP etched. Samples A and C were also highpressure water rinsed. Various amounts of carbon and oxides were present. Carbon on the surfaces was mainly from the ambient and was likely in the carbonaceous form since it peaks at a binding energy $\geq 285.3 \mathrm{eV}$. Some hydroxide was also present. For oxides, $\mathrm{Nb}_{2} \mathrm{O}_{5}$ dominated, while the amounts of the $\mathrm{Nb}$ metal varied.

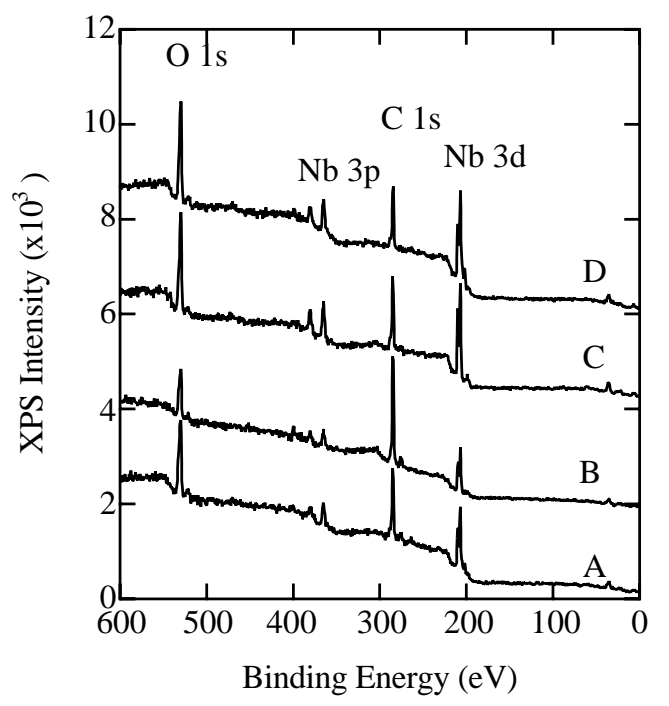

Figure 1: XPS spectra of as-received Nb samples.

\footnotetext{
* The work is supported by the U.S. Department of Energy, Office of Basic Energy Sciences under contract No. W-31-109-ENG-38.

† qingma@aps.anl.gov
} 
No significant differences were attributable to different surface treatments (EP or BCP). The thickness of the ooverlayer on $\mathrm{Nb}$ was estimated to be $\sim 5 \mathrm{~nm}$ by measuring the $\mathrm{Nd} 3 \mathrm{~d}$ peaks at different escape angles of the photoelectrons. For photoelectrons with kinetic energies near $1050 \mathrm{eV}$, the electron mean free path was $\sim 2 \mathrm{~nm}$ [2]. These samples appeared to have relatively thick oxides, which may be due to the long period of time after initial processing at CERN; the samples were analyzed 5 months later. Recent work carried out on samples prepared in our laboratory shows that the oxides are typically $\sim 2$ to $3 \mathrm{~nm}$ thick for a short time in the air, say a few hours to a day.
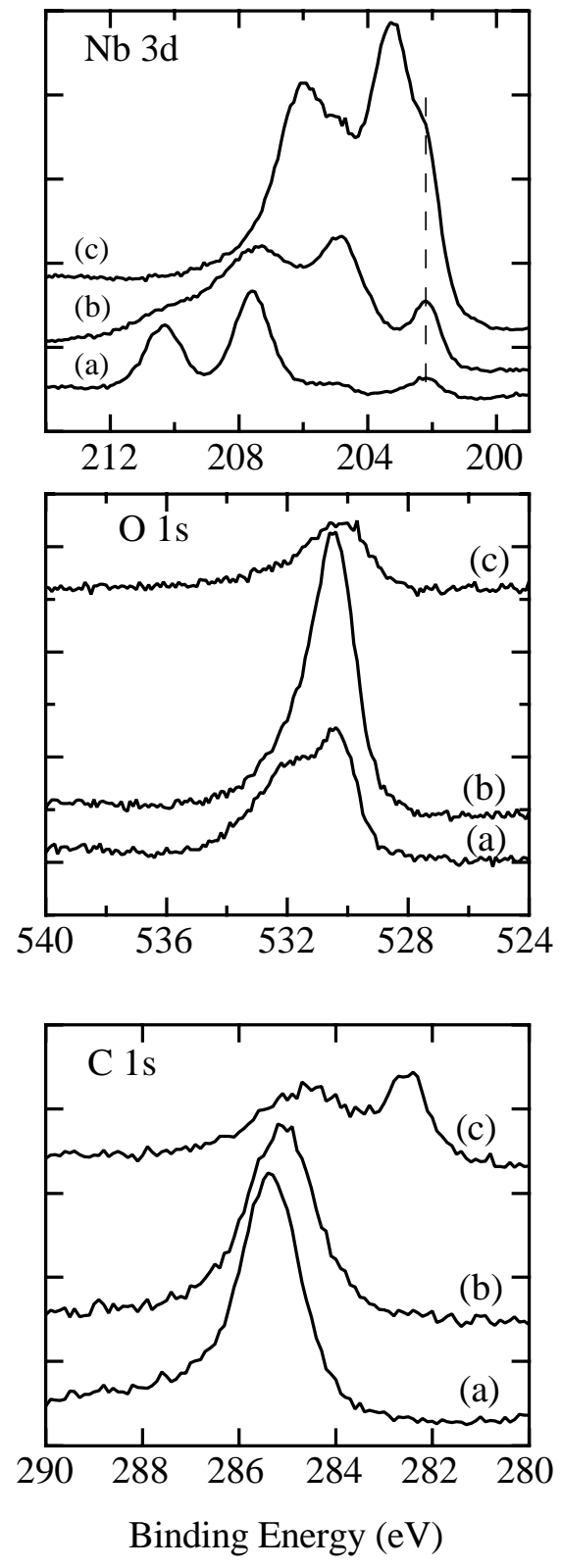

Figure 2: XPS spectra of $\mathrm{Nb} 3 \mathrm{~d}, \mathrm{C} 1 \mathrm{~s}$, and $\mathrm{O} 1 \mathrm{~s}$. (a) as received. (b) $3 \mathrm{~h}$ heating at $250{ }^{\circ} \mathrm{C}$. (c) $19 \mathrm{~h}$ heating at $250{ }^{\circ} \mathrm{C}$. The dashed line in $\mathrm{Nb} 3 \mathrm{~d}$ indicates the $\mathrm{Nb}$ metal $3 \mathrm{~d}$ peak.
All of the samples were subjected to heat treatment at $250{ }^{\circ} \mathrm{C}$ after initial XPS analysis. The surfaces were monitored by XPS during the heating. Figure 2 presents the spectra following (b) 3-h heating and (c) 19-h heating compared with (a) initial surface for the sample A.

The heating effect on the surface was complex. After 3$h$ heating, surface carbon decreased somewhat. There was a clear shift of the C 1s peak to lower binding energy, which indicated possible decomposition of carbonaceous species and rearrangement of carbon atoms toward formation of a new structural entity. When heated, $\mathrm{Nb}_{2} \mathrm{O}_{5}$ also began to decompose and to convert to $\mathrm{NbO}_{2}$ and $\mathrm{NbO}$. The metal signal increased as well. Hydroxide decomposition was indicated by the disappearance of the high-binding-energy shoulder originally existing in the $\mathrm{O}$ 1s line of the as-received sample. We concluded that part of the oxygen released from hydroxide remained and reacted with $\mathrm{Nb}$ on the surface since the peak analysis showed that the ratio of oxide to metal increased slightly (from 7.3 to 8.3).

After 19-h heating at $250{ }^{\circ} \mathrm{C}, \sim 50 \%$ of the total carbon atoms reacted with $\mathrm{Nb}$, and metal carbide formation occurred, as evidenced by the $\mathrm{C} 1 \mathrm{~s}$ peak of carbide at 282.5 $\mathrm{eV}$. The rest of the carbon formed a graphitic state with a binding energy of $284.6 \mathrm{eV}$. A drastic change of the oxide also occurred, and nearly all the oxides converted into a form whose $\mathrm{Nb} 3 \mathrm{~d}$ binding energy was $1.1 \mathrm{eV}$ above that of the metal $(202.1 \mathrm{eV})$. The differences were even smaller for other samples studied. Referring to the binding energies of various oxides [5] and by interpolation, we assigned this oxide to be $\mathrm{Nb}_{2} \mathrm{O}$. The metal signals further increased in that the ratio of the oxide to metal is now $\sim 4.8$. This result suggests that with heating some oxygen is lost during the oxide conversion.

In the XPS data simulation we considered the so-called singularity effect on the photoemission lineshape of a metal due to many-body events near the Fermi level. This effect produces a tail attached to the higher binding-energy side of the photoemission peak of the metal. This tail can be accounted for by a Doniach-Sunjic function containing a singularity factor $\alpha$. Interestingly, the $\mathrm{Nb}_{2} \mathrm{O} / \mathrm{Nb}$ spectrum, the $\mathrm{Nb} 3 \mathrm{~d}$ curve (c) of Fig. 2, can be best fit using two Doniach-Sunjic functions, both with $\alpha=0.11$, a value nearly identical to that found for the $\mathrm{Al} 2 \mathrm{p}$ line of the $\mathrm{Al}$ metal [3] or for the $\mathrm{C}$ 1s line of graphite [4]. It is thus suggested that $\mathrm{Nb}_{2} \mathrm{O}$ may be rather metallic in nature. Figure 3 is used to show the simulation results.

To determine whether the metal peaks are associated with the bulk substrate or with segregates embedded in the oxide, angular-resolved XPS measurements were performed on the 19-h annealed surface. In addition to measuring the photoelectrons escaping along the surface normal, the XPS spectra are obtained by collecting the photoelectrons along the direction of 40 degrees to the surface normal. In this spectrum (not shown), the shoulder near $201 \mathrm{eV}$, associated with $\mathrm{Nb}$ (see Fig. 3), is drastically attenuated. Thus, the $\mathrm{Nb}^{\circ}$ signals are from the bulk $\mathrm{Nb}$. 


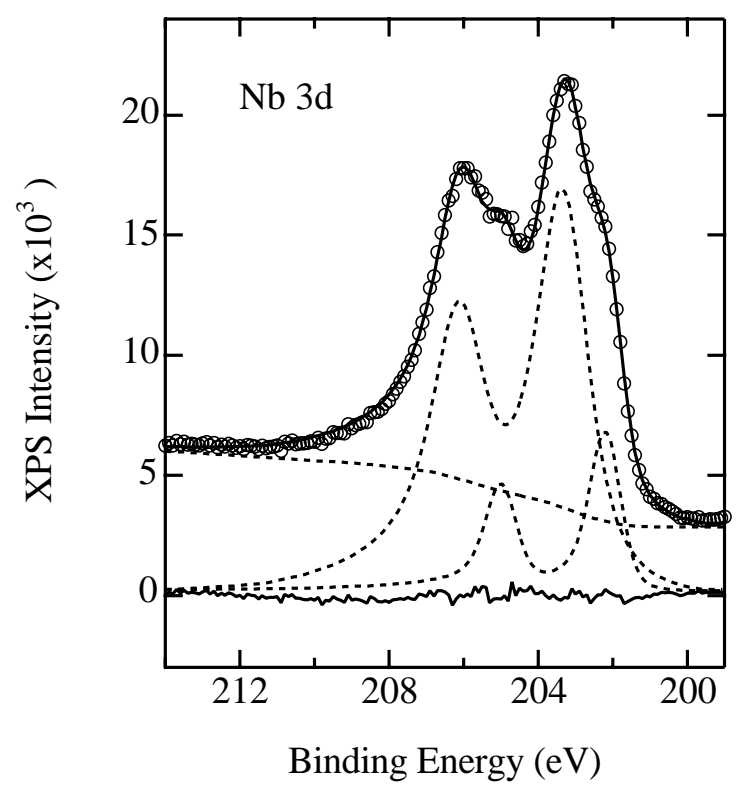

Figure 3: Simulations of the $\mathrm{Nb} 3 \mathrm{~d}$ spectra of the $\mathrm{Nb} 2 \mathrm{O} / \mathrm{Nb}$ by using two Doniach-Sunjic functions. The branch ratio of $\mathrm{Nb} 3 \mathrm{~d}_{5 / 2}$ and $3 \mathrm{~d}_{3 / 2}$ is $1.6 \mathrm{eV}$ and the spin-orbit splitting is $2.8 \mathrm{eV}$.

Thermal effects on the surface oxide of $\mathrm{Nb}$ were studied previously [5, 6]. For oxides with thicknesses $\geq 11 \mathrm{~nm}$ and anodically formed on $\mathrm{Nb}$, a complete conversion of $\mathrm{Nb}_{2} \mathrm{O}_{5}$ into $\mathrm{NbO}$ was seen at temperatures $\geq 400^{\circ} \mathrm{C}$ within a few minutes. It was concluded that thick $\mathrm{Nb}_{2} \mathrm{O}_{5}$ layers are not stable with the measured activation energy of $174 \pm 6 \mathrm{~kJ} / \mathrm{mol}$ and that the reduction of the oxide was initiated by dissolution of oxygen into the bulk of the material. The results presented here are different in various aspects. A more complex picture is obtained. It directly or indirectly suggests that the process at $250{ }^{\circ} \mathrm{C}$ involves thermal dissociation (hydroxide and hydrocarbon), thermal desorption (volatile species), elemental inter-diffusion (as evidenced by carbide formation), oxide reduction (as evidenced by $\mathrm{Nb}_{2} \mathrm{O}$ formation), etc. However, there is no firm evidence that a rapid dissolution of oxygen into the bulk has occurred except for a slight increase of the ratio of oxide to $\mathrm{Nb}^{\circ}$ at initial heating. Heating longer results in the decreased ratio of oxide to $\mathrm{Nb}^{\circ}$, which suggests a loss of the oxygen. Our recent work, which will be presented elsewhere, indicated that for a $\mathrm{Nb}_{2} \mathrm{O}_{\mathrm{x}} / \mathrm{Nb}$ surface $(\mathrm{x} \leq 1)$ obtained after thermal annealing, further heating at $250{ }^{\circ} \mathrm{C}$ indeed increased slightly the ratio of oxide to $\mathrm{Nb}$, from which a diffusion coefficient of the order of $10^{-22}$ $\mathrm{cm}^{2} / \mathrm{sec}$ was estimated.

Secondary electron yields of as-received surface and 19h, $250-^{\circ} \mathrm{C}$ annealed surface are compared in Fig. 4. The annealed surface has a much lower SEY, indicating a more conducting surface. This result supports the conclusion obtained from the XPS analysis that $\mathrm{Nb}_{2} \mathrm{O}$ is quite metallic in nature. Note that some carbide and graphitic carbon formed on the surface contribute to an overall low
SEY, as well. Angular-resolved XPS data also indicated that carbide is underneath the graphitic carbon.

Some of the CERN samples showed a slower response to annealing at $250{ }^{\circ} \mathrm{C}$. Thus, the stability of $\mathrm{Nb}_{2} \mathrm{O}_{5}$ may vary due to a structural origin that cannot be revealed by XPS. Our recent work on samples, etched and exposed to air for a few hours or a day, shows a similar response to that described in this paper. One focus for future studies will be to pinpoint the structural origin of the instability or stability of $\mathrm{Nb}_{2} \mathrm{O}_{5}$ on $\mathrm{Nb}$.

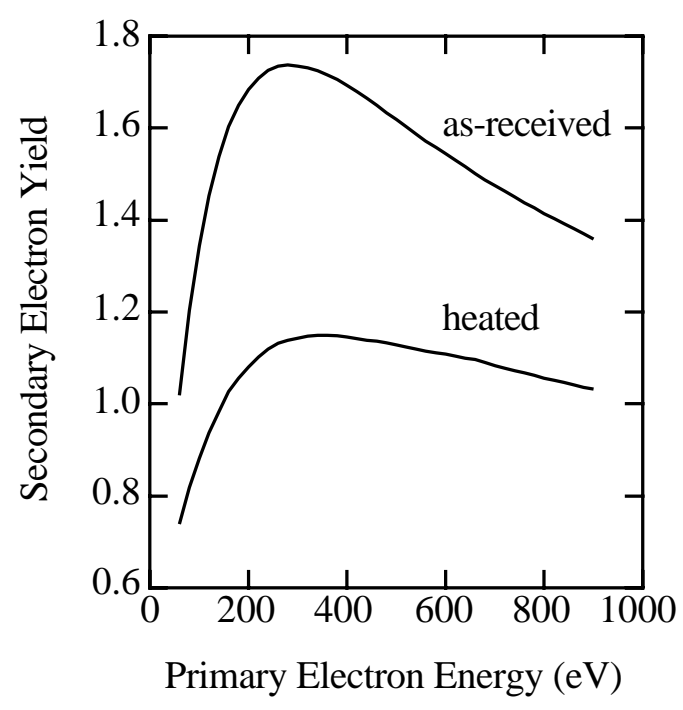

Figure 4: Secondary electron yields from as-received and $19-\mathrm{h}, 250-{ }^{\circ} \mathrm{C}$ annealed surfaces.

\section{CONCLUSIONS}

Thermal responses of the oxide/ $\mathrm{Nb}$ systems are studied. By annealing at $250{ }^{\circ} \mathrm{C}$ the native $\mathrm{Nb}_{2} \mathrm{O}_{5}$ oxide on $\mathrm{Nb}$ can be reduced to $\mathrm{Nb}_{2} \mathrm{O}_{\mathrm{x}}(\mathrm{x} \leq 1)$. Some of the surface carbon originally on the surface is transformed to graphitic carbon and $\mathrm{Nb}$ carbide. The process leads to a surface that is much better conducting than the initial native surface and that has a low SEY. These results should provide knowledge that will be useful for understanding the effects of thermal treatments on cavity surfaces.

\section{ACKNOWLEDGMENTS}

We would like to thank Stefan Ehmele at CERN and Lutz Lilje at DESY for sample preparation.

\section{REFERENCES}

[1] E.L. Garwin et al., J. Appl. Phys. 61, 1145 (1987).

[2] S. Tanuma et al., JVST A 6(3), 1041 (1988).

[3] Q. Ma and R.A. Rosenberg, Surf. Sci. 391, L1224 (1997).

[4] Q. Ma and R.A. Rosenberg, Phys. Rev. B 60, 2827 (1999).

[5] B.R. King et al., Thin Solid Films 192, 351 (1990).

[6] A. Dacca et al., Appl. Surf. Sci. 126, 219 (1998). 